\title{
Pride Learning Model in Order to Improve the Physical Fitness of Indonesian Naval Academy Cadets
}

\author{
Suryono $^{1}$, I Made Sriundy Mahardika ${ }^{2}$, Abdul Rachman Tuasikal ${ }^{2}$ \\ ${ }^{1}$ Master Student in Sport Education, Universitas Negeri Surabaya, Indonesia \\ ${ }^{2}$ Lecturer in Sport Education, Universitas Negeri Surabaya, Indonesia \\ Suryono13644@gmail.com
}

\begin{abstract}
Physical fitness lesson that consists of freestyle swimming material, road and field, physical fitness test are one of the practical subjects, becoming one of the aspects that determine the graduation of cadets in the Indonesian naval academy. In order to improve cadets physical fitness, researchers develop a pride learning model using the following stages; $(P)$ understanding concepts, (R) Reflection, (I) Implementation, (D) Drill, and (E) Evaluation. The purpose of this study is to analyze (1) the product of the pride learning model to improve physical fitness, (2) the effectiveness of the pride learning model to improve freestyle swimming abilities, (3) the effectiveness of the pride learning model to improve physical fitness test abilities, $(5)$ the difference in effectiveness of the pride learning model compared to old learning. Research type used is research and development, by developing a product and quantitative compared to the documents of the results of the pre-test and post-test groups that are not treated by the learning model. The design and analysis of this study uses Anova. The data collection process uses a T-test for the 50 meter freestyle swimming test, road and field 3000 meters and physical fitness test during the pre test and post test. The results of the study based on the T-test shows that the calculated value between the pre-test and post-test of the group that is not given treatment and that was given treatment with the pride learning model were, (1) the untreated group 76,89 freestyle, 77, 05 road and field and 162.11 physical fitness tests, (2) groups treated with 80.84 freestyle swimming, 82.74 road and field and 269, 47 physical fitness test. Based on the above analysis, it can be concluded that the pride learning model the results of the development of relevant researchers are used in physical fitness learning because there are more differences in results in the treated group than the untreated group. In addition, it can improve the ability of free style swimming, road and field and physical fitness test seen from the results of the T-test.
\end{abstract}

Keywords

pride learning model; physical fitness free style swimming road and field fitness test

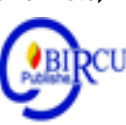

\section{Introduction}

The Indonesian Navy's National Army Academy (AAL) is one of the formal educational institutions in the Indonesian Navy that aims to produce cadets of candidates for the Navy Academy Academy as an officer candidate for leadership in the Navy, in the future it is expected to have the knowledge and basic technical skills of the profession soldiering and have a good physical kesamaptaan. So after completing his education at the Naval Academy for 4 years the cadets are expected to be able to; behave and behave as a Sapta Marga warrior in every activity able to master the scientific basics and skills in the scope of the respective corps (Sailors, Engineering, Electronics, Supply and Marines), applying knowledge and sea defense 
defense management skills according to procedures which applies well and correctly, and carries out personality development as a cadre of leaders according to the norms that apply properly and correctly and maintains physical security in accordance with the standards of physical development of the TNI / TNI Navy.

If from some of these goals and objectives can be embedded in the attitudes, actions and behavior of Youth cadets, graduates of the Navy Academy Youth Academy as qualified officers can be met so that The Indonesian Navy Academy as one of the formal educational institutions in the Indonesian Navy is in line with the World Class Navy in accordance with its vision and mission. Besides, the main tool of the weapons system which must be updated and no less important is human resources, in this case graduates of quality officers from the Navy Academy so that they are capable of knowledge, skills and physical readiness who will be able to maneuver according to their field of work later on unity.

The ability of physical safety in the education of the Naval Academy of the Indonesian Navy is one of the absolute abilities that must be nurtured and formed because it is the main ability in the assignment in the unit. The aspect of physical safety in the education of the Naval Academy of the Indonesian Navy is an important aspect because at the end of every education and per semester it will be an aspect of assessment that also determines the success of Cadets whether to advance or not. The aspect of physical safety in the education of the Naval Academy of the Indonesian Navy is an important aspect because at the end of every education and per semester it will be an aspect of assessment that also determines the success of Cadets whether to advance or not. Each level or level of education of the Naval Academy of the Indonesian Navy Navy teaching material / physical safety lecture is given according to the level, such as; level II teaching materials consist of semesters 3 and 4 (50 meter freestyle swimming, road and field skills and physical safety test), level III teaching materials semester 5 and 6 (100 and 200 meter freestyle swimming, cross country skills and safety tests physical) level IV semesters 7 and 8 (swimming freestyle fin swimming 800 meters, military selfdefense skills and obstacle courses and physical safety tests).

Based on data on physical fitness evaluation results including 50 meter freestyle swimming, road and field skills and physical fitness tests for cadets at level II starting in 2017, 2018 and 2019 above there are still many cadets who score with the C +, C, D and E categories, namely in 2017 there were 40 cadets, in 2018 there were 69 cadets and in 2019 there were 49 cadets. Data on the results of physical evaluation of cadets who get $\mathrm{C}+, \mathrm{C}, \mathrm{D}$ and $\mathrm{E}$ categories can actually be improved so that later they will achieve a minimum score with good categories (B). One of the ways to improve the achievement of Taruna physical fitness scores is to improve the learning of physical welfare materials (freestyle swimming, road and field and physical safety test) that are more innovative and creative. The learning must be prepared by lecturers / trainers with good planning and given in a systematic learning model like Ibrahim's opinion (Giri Wiarto, 2015), namely: State learning planning is an activity to formulate the goals achieved by a learning activity, what methods are used to assess the achievement of these objectives, what material will be delivered, how to convey, and what tools or media are needed. While the physical safety learning model for cadets at the TNI Navy Academy has so far been carried out by means of conventional learning models that are learning done in sequences of learning such as preparing, leading to pray, absent, explaining techniques, practicing, evaluating, and closing lessons.

Meanwhile, to improve the ability of the physical abilities of Youth cadets can be done with efforts to create new learning models that are more innovative and creative. Efforts to create the learning model must be done because based on the results of preliminary research 
through questionnaires to cadets level IV, III who have experienced during level II and cadet level II who are participating in learning physical safety material (50 meter freestyle swimming, road and field and physical safety test) as many as 30 cadets who have represented each corps and each level is taken 10 cadets with composition of 5 cadets who get good categories and 5 cadets who get less categories, that they want physical learning as follows:

1. The movement of physical material teaching material which is taught is still having difficulty practicing

2. The lecturer / trainer has not yet given an understanding of the concept of physical safety subject matter about the correct movement techniques using video assistance.

3. The lecturer / trainer in conveying physical welfare lesson material is still monotonous and less creative

4. Cadets want an innovative learning model to make it easier to understand and practice physical safety subject matter.

5. The practice of physical welfare material training does not support the achievement of results at the time of evaluation and physical safety test at the end of each semester.

6. Cadets in understanding the correct movement techniques on material physical safety have not been given the opportunity to explain concepts that are understood to other cadets by means of theory or dry practice.

7. Need to be given physical fitness guidance that has to do with physical welfare material outside of class hours with weight training.

Based on the results of the preliminary research, it has become a necessity to plan a more innovative physical safety learning model to be given to Youth so that it can improve the evaluation results at the end of learning and semester by getting minimal results with good categorical grades. Based on the duties and responsibilities that must be carried out by the Navy in its assignment field, it must be supported by officers who have quality as managers within the scope of their units. Observing the description of the main tasks of the Navy, there are two main things that must always be developed and improved in the face of tactics and strategies that must adjust the dynamics of development in the field.

First, the main tool of the weapons system (defense equipment) and secondly, the problem of human resources (HR) in this case the Officer as manager in the part / unit of his assignment. Both of these problems must always be developed to be better in order to achieve the ideals of becoming a world class navy (World Class Navy) that will play a role and contribute in the field of defense both at Regional and International level. The Navy has a duty as a means of defense of the sea dimension obviously being considered in addition to the problem of the main weaponry system and especially human resources as its bodyguard. Human Resources especially must always be nurtured and prepared especially from the aspect of physical safety because of the demands in the assignment later an Officer must be a manager and leader who, besides being superior, must also be an example among the soldiers he leads.

The aspect of physical safety that supports to produce reliable human resources held at the Indonesian Navy Academy is one of the benchmarks in every educational output produced. Based on data from Taruna's physical safety and the preliminary research described above, it shows that the quality of physical safety of Taruna graduates at the Indonesian Navy Academy is not entirely as expected. This can be seen from each evaluation at the end of the semester there are still many physical achievement results of cadets who still get grades with less categories, the allocation of learning time for 1 semester credit system (SKS) consisting of 32 hours of learning needs to be handled appropriately and correctly, the learning material provided Taruna has not touched the components that will be assessed when the assessment is 
held at the end of the semester, additional time in the framework of coaching to achieve the final assessment results have not been optimally utilized and the learning models provided are not yet innovative and creative to foster and develop the components that are created. end of semester tested.

Based on the illustration above, the aspects of physical abilities in cadets become aspects that need to be fostered and developed with a more innovative and creative physical safety learning model in order to obtain learning outcomes in accordance with the expected goals and objectives of producing a Navy Officer who has the ability of aspects of his physical kesamaptaan to face in the scope of his assignment. The learning process of a subject, especially physical education both theoretically and practically, requires a learning model that will facilitate teachers to transfer their experience and knowledge to their students. Understanding the learning model is defined by several experts in presenting a matter, according to J oyce (Giri Wiarto 2015,77) learning model:

Learning model is a plan or a pattern that is used as a guide in planning learning in class or learning in tutorials and to determine learning tools including books, films, computers, curriculum and others.

Meanwhile according to Soekamto, et al. (Giri Wiarto 2015,77) learning models have meaning, namely: Learning model is a conceptual framework that describes a systematic procedure in organizing learning experiences to achieve certain learning goals, and serves as a guide for learning designers and instructors in planning teaching and learning activities.

Arend (Trianto 2011,5) adds understanding of learning models stating that The learning model leads to a particular learning approach including its objectives, syntax, environment and management system.

Meanwhile according to Nieveen (Giri Wiarto 2015.79) states that a learning model can be said to be good if it meets the following criteria:

a. Valid (valid)

Is the learning model developed based on strong theoretical rational or is there internal consistency.

b. Practical

The practical aspects can only be met with experts and practitioners stating that what is developed can be applied and the reality shows that what is developed can be applied.

c. Effective

It is said to be effective if experts and practitioners based on their experience state that the model is effective and operationally the model provides results that are as expected.

Still according to Giri Wiarto $(2015,96)$ while the stages of the design of the learning system ADDIE learning model are formulated as follows:

a. Analyze

Implementation of learning programs or management improvement, whether the problem is really a problem and requires efforts to resolve.

b. Design

How an instructional designer is able to determine what learning experiences or learning experiences that need to be owned by teachers while participating in learning activities.

c. Develop 
That an instructional designer must have the ability to include activities to choose and determine methods, media and learning strategies that are appropriate for use in delivering the material or substance of the learning program.

d. Implement

How instructional designers are able to choose what learning methods are most effective in conveying learning materials or materials.

e. Evaluate

How an instructional designer is able to evaluate the entire model, from the beginning to the end.

Lecturers / instructors in an effort to foster physical abilities of cadets must first know the physical or biomotoric components that must be trained. According to Nala $(2011,15)$ states the ten components of biomotor ability or physical fitness referred to, as follows:

a. Cardiovasculair Endurance

b. Muscle Endurance

c. Muscle Strength

d. Flexibility

e. Body Composition

f. Speed of Movement

g. Agility

h. Balance

i. Reaction Speed

j. Coordination

Based on Taruna education curriculum at the Indonesian Navy Academy aspects of physical safety assessment must absolutely meet the graduation standards, in accordance with the curriculum for material learning of physical safety Taruna level II in semesters 3 and 4 consisting of 50 meter freestyle swimming, road and field 3000 meters without load and 3000 meters with weights and physical safety tests, in detail the learning material will be explained further as follows: the ten basic components, cadets at the Indonesian Navy Academy can be fostered and improved through teaching materials at level II such as freestyle swimming with drill, road and field training with Fartlek training and physical safety tests and physical training (weight training) outside scheduled class hours. So it is expected that cadets can achieve the results of their physical abilities at the time of the evaluation test of teaching material given to get better results. The Navy Academy Youth Academy after completing its education is expected to have the ability of academic aspects (Responsiveness), personality (Tanggon) and physical security (Trengginas), so that if these three aspects can be possessed then the benchmarks as qualified officers can be fulfilled to carry out tasks the principal of the Navy in the KRI, Staff and Troop.

\section{Research Method}

The research used is a type of research and development or Research and Development (R\&D). According to Gal \& Borg $(2003,569)$ research and development can be interpreted as follows: Development research is a study that is designed to produce new products and procedures, which are carried out systematically in field testing, evaluation and filtering to find specific criteria, quality and approaching. the standard. Furthermore, this development research will be followed up with action research, according to Zuriah $(2003,54)$ stating that: Action research is research that emphasizes activities (actions) by testing an idea into real practice or 
situations on a micro scale that is expected to be able to improve, improve quality and improve social quality. Before using the formula, the researcher will first look for the correlation between the effectiveness value and the difference in the old learning model and the innovation learning model of the pride, average, standard deviation and variance models. The researcher will correlate the total value, the effectiveness value and the difference then do the calculation with SPSS so that the prices needed to calculate $t$ can be obtained. The research framework is presented in Figure 1.

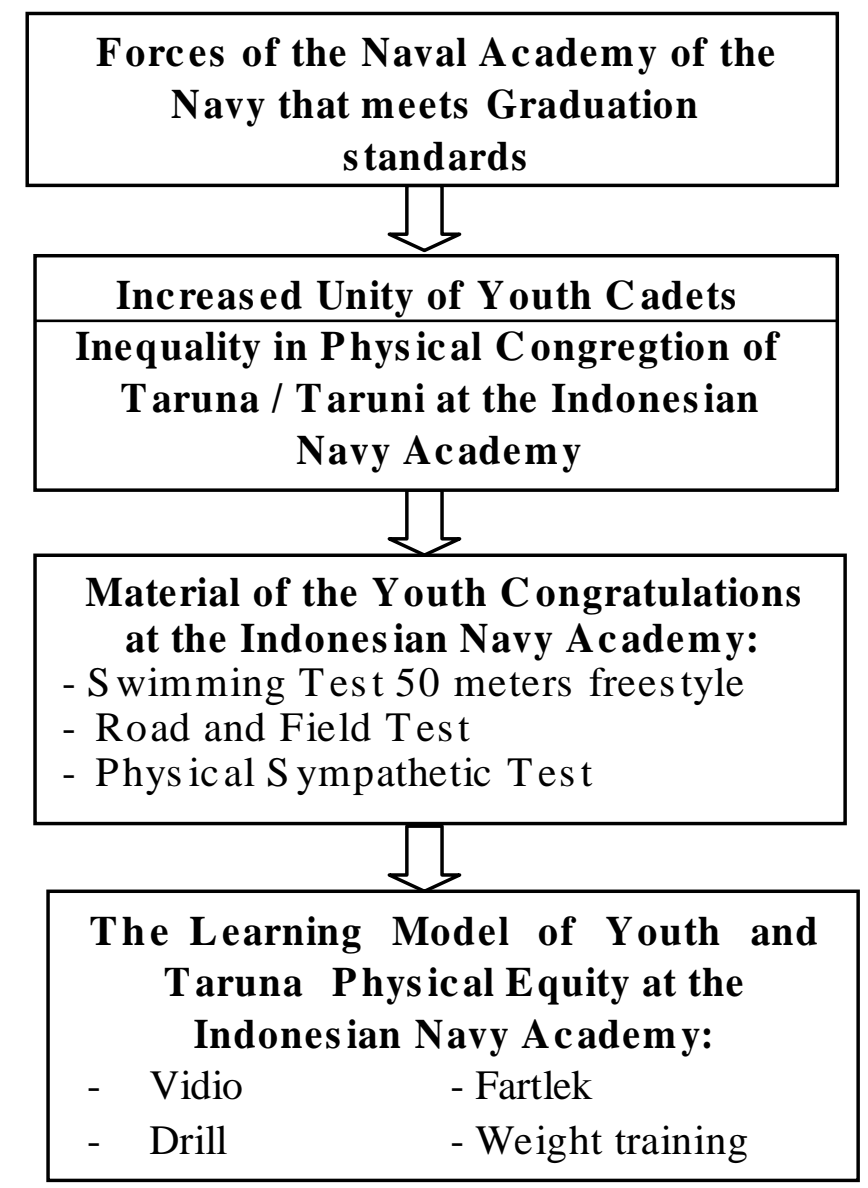

Based on the calculation results obtained from the results of the experts' validation the average score of each item is $(-0.67,-0.33$ and 0$)$ which is between the values of 1 and -1 and enter the relevant criteria, thus the pride learning model relevant can be tested and used in physical safety learning for cadets.

\subsection{Data Normality Test}

Based on the SPSS calculation results, that the variable Pool, Road and Field and Physical Fitness has a significance value> 0.05 (Accept Ho), meaning that the data from the variable has a normal distribution.

\subsection{Data Reliability Test}

Based on the SPSS calculation, that the variable of freestyle swimming, road and field and Cronbach's Alpha physical fitness tests $>0.7$ so that the data is reliable / reliable to use. 


\subsection{Data Homogeneity Test}

Based on the homogeneity test of the pre test data and the 50 meter freestyle swimming test post with treatment and without treatment the learning model has a significance value of $0.161>0.05$ (accept Ho), meaning that the variant of the 50 meter freestyle swimming pool test data both given treatment or without being treated with the learning model the value is the same (homogeneous).

\section{Discussion}

Based on the homogeneity test of pre-test data and the road and field test post with a distance of 3000 meters with treatment and without treatment the learning model has a significance value of 0.554>0.05 (accept Ho), meaning that the variant of road and field test data of 3000 meters with both treatments given or without being treated with the learning model the value is the same (homogeneous). Based on the homogeneity test of pre-test data and physical fitness test post with treatment and without treatment the learning model has a significance value of $0.283>0.05$ (accept Ho), meaning that the variance of physical fitness test data whether given or not treated with the learning model homogeneous.

Based on the results of different tests on the results of the 50 meter freestyle swimming test with treatment and without treatment thePride learning model obtained a significance value of 0.044 that is $<0.05$ (reject Ho), meaning that there is a difference between the 50 meter freestyle swimming test results given treatment and not given treatment with the Pride learning model. The results of freestyle swimming scores were not given the treatment of the learning model Pride $=76.89$ while those given the treatment with the learning model Pride $=80.84$. This shows that the results of the 50 meter freestyle swimming test scores given the treatment of the Pride learning model are more effective by showing the results of the improved test scores.

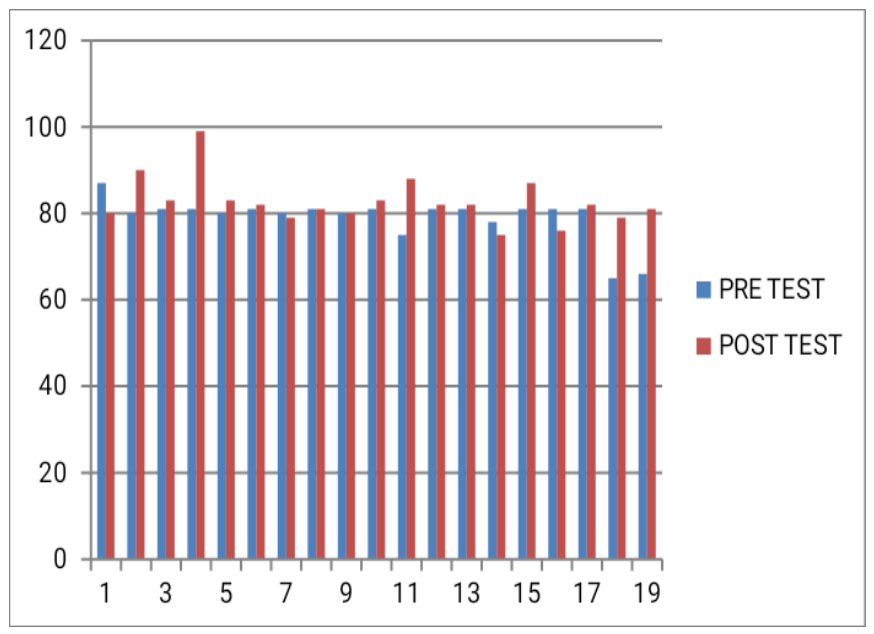

Difference in Results of Freestyle Swimming Test Scores 50 Meters with Treatment and without Model Treatment Pride Learning.

Based on the results of different tests on the results of the road test and field distance of 3000 meters with treatment and without treatment the Pride learning model obtained a significance value of 0.002 namely $<0.05$ (reject Ho), meaning that there is a difference between the results of the road and field test distance of 3000 meters given treatment and not given treatment with the Pride learning model. The results of the road and field values were not 
given the treatment of the learning model Pride $=77.05$ while those given the treatment with the learning model of the Pride $=82.74$. This shows that the results of the road and field test scores of 3000 meters given the treatment of the Pride learning model, are more effective in showing the results of improved test scores.

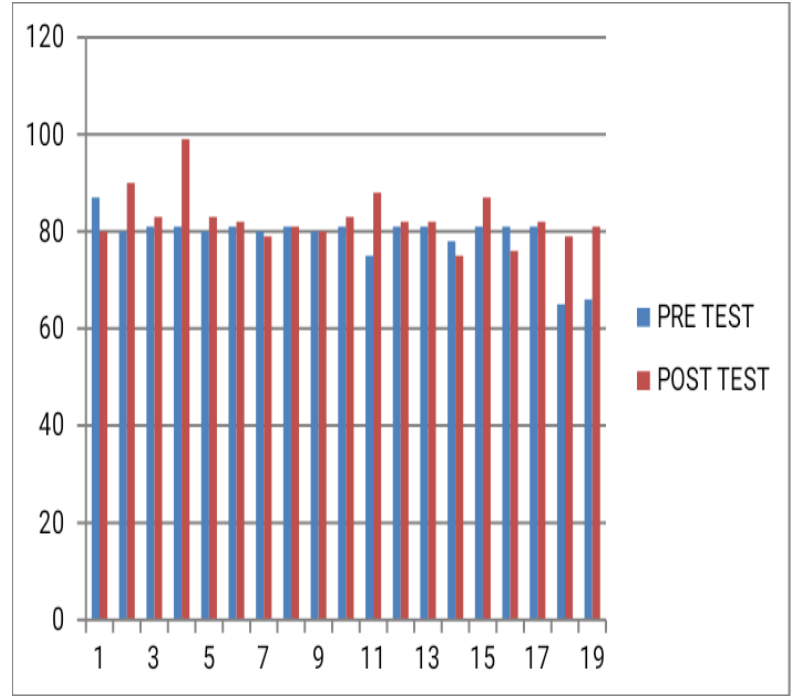

Difference between Physical Fitness Test Score Results with Treatment and Without Treatment Pride Learning Model.

\section{Conclusion}

Based on the results of research and discussion of the pride learning model in an effort to improve physical abilities in the material freestyle swimming, road and field and physical fitness tests that have been described in the previous discussion, it can be summarized research, as follows:

1. The pride learning model is relevant and important in an effort to improve physical abilities in the material of freestyle swimming, road and field and physical fitness tests for Second Level Marine Cadets at the Naval Academy.

2. The pride learning model is more effective to improve the results of achievement in freestyle swimming subject matter.

3. Pride learning model is more effective to improve the results of achievement in road and field subject matter.

4. Pride learning model is more effective to improve the achievement results on the subject matter of physical fitness tests.

5. There is a difference in results between cadets who are treated with pride learning models compared to those who are not given pride learning treatments. The difference in results in free style swimming is the cadets group that was not given treatment 76.89 while those given 80.84 treatment, there was an increase of 3.95, the difference in the results in the road and field group cadets who were not given 77.05 treatment while those who were given 82 treatment , 74, there was an increase of 5.69, while in the physical fitness test the cadets group was not given 162.11 treatment while the group given 169.47 treatments, there was an increase of 7.36 . 


\section{References}

A Taufik. R. 2014. World Class Navy Naval Academy. Surabaya: Indonesian Navy Academy. David G. Thomas. 2006. Beginner Level Swimming. J akarta: P.T. Rajagrafindo Persada. Zdikar Dikdik Dikdik. 2014. Teach and Train Athletics. Bandung: P.T. Teen Rosdakarya. Giri Wiarto. 2015. Learning Innovation sin Physical Education. Yogyakarta: Laksitas.

I Gusti Ngurah Nala.2011. Principles of Physical Sports Training. Bali: Udayana University Press.

Decree of the Commander of the Indonesian Armed Forces. Technical Guidance for Examination and Test of Indonesian National Army Officer Candidates, Kep / 982 / XII / 2013: J akarta: 12 December 2013.

Governor's decree. 2014. Instructions on the Implementation of Learning Outcomes of Academic Study Cadets of the Indonesian Navy, Kep / 16 / III / 2014: Surabaya: March 06, 2014.

Kasal Decision. 2007. Curricula Educa-tion Curriculum for Military Academy Youth Level I Phase II, III and IV FY 2016, Kep / 219 / XII / 2016 Number: J akarta: 29 December 2016.

Moleong, L.J .2006. Qualitative Research Methodology. Revised Edition. Bandung: P.T. Teen Rosdakarya.

John W. Creswell.2015. Research Design Qualitative, Quantitative, and Mixed Approac-hes. Yogyakarta: Student Library.

Roesdiyanto S.2008. Fundamentals of Sports Coaching. Malang: Laboratory of Sports Science, State University of Malang.

Sugiono.2016. Educational Research Methods. Bandung: Alfabeta. 13. Sujarwo. 2011. Kesamaptaan Module. Yogyakarta: Yogyakarta State University.

Trianto.2011. Constructive-Oriented Innovative Learning Models. J akarta: Literature Achievement.

Republic of Indonesia Law No. 34/2004 concerning the TNI. J akarta.

Maulana.2018. Benefits of Freestyle Swimming With Its Understanding and Technique. $\quad$ Focussatu.com.https://fokussatu.com/benefit-brant-style-bebas-beserta undertanding-and- technique / February 182019.

Sartika.2019. The Benefits of Freestyle Swimming to the Body. Benefit.htmlhttps: // Benefit.my/ Benefit- swim-style- free February 182019.

Fadriana.2016. Fast Walking Techniques. Related Posts. .https: //beritaolahratercomplete01.blogspot.com/2016/11/peng understanding-walk-fast.html 18 February 20 